\title{
ANÁLISE ATUAL DAS TRAJETÓRIAS OCUPACIONAIS DE TRABALHADORES INFORMAIS DA CONSTRUÇÃO CIVIL EM BELÉM DO PARÁ (2018)
}

\author{
José Raimundo Trindade ${ }^{1}$ \\ Carla Caroline Barisão de Souza²
}

RESUMO: A análise das trajetórias ocupacionais de trabalhadores informais constitui uma tarefa fundamental para compreensão das alterações pelas quais o Brasil passa, inclusive considerando a nova realidade que emerge desde as profundas alterações legais, econômicas e sociais ocorridas nos últimos três anos. Os trabalhadores aqui enfocados fazem parte do contingente de força de trabalho informalmente empregada na construção civil, segmento importante da economia brasileira e local. A pesquisa de campo ocorreu nos meses de setembro e outubro de 2018 em que foram entrevistados 03 (três) trabalhadores homens em suas residências, que aceitaram participar da pesquisa, conforme termo de esclarecimento, assinado por ambas as partes, pesquisador e entrevistado. A questão central que norteou a pesquisa foi: quem são como vivem e o que pensam os trabalhadores informais da construção civil da periferia de Belém? Com base nas entrevistas foi possível estabelecer alguns parâmetros de análise: i) os entrevistados são unânimes em afirmar que as condições de trabalho nas empresas, ou seja, quando os mesmos estiveram empregados formalmente, são muito precárias e não apresentam "vantagens" ao emprego informal, exceto quanto aos aspectos de intermediação e, em alguns casos, a garantia do pagamento do INSS; ii) não há, pelo menos a partir da história de vida dos entrevistados, barreiras técnicas entre a construção civil formal e informal, o que nos remete a duas ordens de questões: primeiro, a baixa tecnicidade da construção civil brasileira ou pelo menos paraense e; segundo, a formação e qualificação dos trabalhadores se dá em grande medida pelo processo de autoaprendizagem; iii) o grau de intensidade no trabalho constitui o ponto central da diferenciação entre um "regime formal ou quase formal" e o "regime informal de trabalho", porém em ambos os casos as jornadas são superiores as 40 horas semanais tomadas como padrão médio e legal ainda vigente no país.

Palavras-Chave: Informalidade; Construção Civil; Relações de Trabalho; Belém.

\section{CURRENT ANALYSIS OF THE OCCUPATIONAL TRAJECTORIES OF INFORMAL CONSTRUCTION WORKERS IN BELÉM DO PARÁ (2018)}

\footnotetext{
ABSTRACT: The analysis of the occupational trajectories of informal workers constitutes a fundamental task for understanding the changes that Brazil is going

1 Professor Associado vinculado ao Programa de Pós-Graduação em Economia (PPGE/UFPA). Universidade Federal do Pará. E-mail: jrtrindade@uol.com.br

${ }^{2}$ Graduação em Serviço Social, Mestrado em Serviço Social e Doutoranda em Economia (UFPA). Email: carol_barisao@yahoo.com.br.
} 
through, including considering the new reality that emerges from the profound legal, economic and social changes that occurred in the last three years. The workers focused on here are part of the workforce contingent informally employed in civil construction, an important segment of the Brazilian and local economy. The field research took place in the months of September and October 2018 in which 03 (three) male workers were interviewed in their homes, who agreed to participate in the research, according to a clarification term, signed by both parties, researcher and interviewee. The central question that guided the research was: who are how they live and what do informal civil construction workers on the outskirts of Belém think? Based on the interviews, it was possible to establish some parameters of analysis: i) the interviewees are unanimous in stating that the working conditions in the companies, that is, when they were formally employed, are very precarious and do not present "advantages" to informal employment, except as regards the intermediation aspects and, in some cases, the guarantee of the INSS payment; ii) there are, at least from the interviewees' life history, no technical barriers between formal and informal civil construction, which leads us to two orders of questions: first, the low technicality of Brazilian civil construction or at least from Pará and ; second, the training and qualification of workers takes place largely through the process of self-learning; iii) the degree of intensity at work constitutes the central point of the differentiation between a "formal or quasi formal regime" and the "informal work regime", however in both cases the hours are more than 40 hours per week taken as the average standard and still in force in the country.

Keywords: Informality; Civil Construction; Labor Relations; Belém.

\section{INTRODUÇÃO}

A análise das trajetórias ocupacionais de trabalhadores informais constitui uma tarefa fundamental para compreensão das alterações pelas quais o Brasil passa, inclusive considerando a nova realidade que emerge desde as profundas alterações legais, econômicas e sociais ocorridas nos últimos três anos.

Convém, mesmo que brevemente, estabelecer considerações sobre as alterações estabelecidas a partir da Lei Complementar 13.467/16, convencionada de Reforma Trabalhista. Os pontos que são mais graves e de repercussão ainda não totalmente visíveis no mercado de trabalho se relacionam a intensificação das condições de fragilidade e vulnerabilidade dos trabalhadores no mercado de trabalho. Vale pontuar na legislação o fortalecimento da figura do trabalho autônomo, intermitente, parcial, temporário e fortalecimento da terceirização.

No chamado contrato de trabalho intermitente, o empregado terá o prazo de vinte e quatro horas para responder ao chamado e o período de inatividade não será considerado como tempo de serviço à disposição do empregador. O trabalhador intermitente somente receberá pelas horas efetivamente ocupadas, o que 
concretamente estabelecerá salários abaixo do mínimo e formas de subemprego enquanto dinâmica legal (KREIN et al, 2018).

Por sua vez o Contrato de Trabalho temporário, será de cento e oitenta dias, consecutivos ou não, prorrogáveis por mais noventa dias, consecutivos ou não, ou seja, será de até 270 dias, bem acima da rotatividade média no Brasil (que é de 6 meses). O resultante desta lógica nos leva ao uso do trabalho temporário enquanto forma definitiva, impondo a definitiva precarização do trabalhador.

Os trabalhadores aqui enfocados fazem parte do contingente de força de trabalho informalmente empregada na construção civil, segmento importante da economia brasileira e local, como se mostra em alguns dados copilados e que, pelas condições já acima brevemente elencadas teremos o provável aprofundamento a partir daqui. As alterações na legislação trabalhista acima referenciada aprofundaram e condicionaram a lógica do que denominamos de informalidade, parte do debate inserido neste artigo se dá já sob este novo desiderato, porém novas repercussões provavelmente ainda se farão sentir.

A pesquisa de campo ocorreu nos meses de setembro e outubro de 2018 em que foram entrevistados 03 (três) trabalhadores homens em suas residências, que aceitaram participar da pesquisa, conforme termo de esclarecimento, assinado por ambas as partes, pesquisador e entrevistado. A questão central que norteou a pesquisa foi: quem são como vivem e o que pensam os trabalhadores informais da construção civil da periferia de Belém?

A metodologia utilizada de entrevista estruturadas-abertas se fez baseado em um conjunto de questões respondidas livremente pelos entrevistados e dispostas conforme cinco eixos fundamentais: i) qual o perfil socioeconômico do trabalhador e de sua família?; ii) qual a trajetória ocupacional do trabalhador no tempo e no espaço até chegar nos dias de hoje?; iii) como são as suas condições de trabalho atualmente?; iv) quais são os atores promotores da informalidade?; v) percepções, perspectivas e posicionamentos políticos. Sob reserva ética as entrevistas foram gravadas, e posteriormente transcritas, e analisadas em par com as anotações postas no diário e campo, sempre sensível à tradição teórica marxista apreendendo os elementos de desenvolvimento desigual e a situação subsumida sobre a classe trabalhadora no debate presente do mundo do trabalho. 
Os entrevistados estiveram e continuam "empregada em tempo de serviço" no setor da construção civil, em sua maioria por mais de 10 anos na ausência de contrato de trabalho, sem embargo a ordem de subsunção do trabalho informal. Isto é, a um arranjo incompleto de emprego, que sobreleva trabalhadores em precárias condições de vida (renda e qualidade de vida). Dado o compromisso em assegurar o anonimato dos pesquisados e, portanto, com a ética na pesquisa - para construção de trajetória de vida na integra, foram identificados por nomes genéricos como Antônio, José e João. Convém ressaltar que a metodologia empregada nas entrevistas foi desenvolvida no âmbito do projeto "Periferias" da Fundação Perseu Abramo.

O artigo está dividido em quatro seções além desta introdução, na seção segunda aborda-se, mesmo que brevemente, aspectos teóricos do significado e importância da chamada economia informal, estabelecendo o entendimento da contraposição a qualquer caracterização de dualismo ou segmentação para esta categoria, apoiada nas percepções desenvolvidas pela Organização Internacional do Trabalho (OIT); na terceira seção, estabelecemos alguns parâmetros e dados relativos ao mercado de trabalho na Região Metropolitana de Belém, tratando de forma ampla o fenômeno da informalidade a fim de, na seção quarta, analisar as entrevistas desenvolvidas e estabelecer elementos para compreender a dinâmica do trabalho informal na construção civil; a quinta seção aprofunda o entendimento da trajetória ocupacional e retira algumas conclusões que, por fim, estão sistematizadas nas considerações finais.

\section{BREVE RETORNO A UM DEBATE TEORICO CRESCENTEMENTE COMPLEXO: A INFORMALIDADE ENQUANTO FORMA ECONÔMICA ESTRUTURAL NO BRASIL}

A informalidade nas relações de trabalho brasileiras tem sido objeto de análise e pesquisas principalmente a partir dos anos 1970, muito embora, no Brasil, ela remonte a conformação do sistema produtivo, ou seja, precede a consolidação das relações formais de capital-trabalho. Não há propriamente uma definição de economia informal, porém observa-se uma compreensão quanto ao sentido estrutural da informalidade nas relações de trabalho estabelecidas no Brasil, segundo parte dos autores a informalidade nas relações de trabalho refere-se ao 
grau de não proteção, regulamentação ou acesso as condições de seguridade social (KREIN, PRONI, 2010; THEODORO, 2005; SENA, 2002; CACCIAMALI, 2000).

Estas relações são caracterizadas por condições precárias de contratação e execução desse trabalho. Diante da gama de definições existentes sobre as atividades informais, foi considerado para este ensaio que a relação informal de trabalho são os indivíduos que estão nas seguintes condições de emprego: trabalhadores sem carteira assinada ou assalariados sem registro em carteira, trabalhadores por conta própria ou autônomos, trabalhadores familiares remunerados ou não, enfatizando os conceitos mais próximo do trabalhador por conta própria, sendo estas relações o foco central da pesquisa de campo. Essas definições de ocupação formam um rol aceito pela literatura concernente a economia informal, sendo adotado aqui como forma de alcançar os objetivos desta investigação (CACCIAMALI, 2000, QUEIROZ, 2015, LEONE, 2010).

No entanto, as análises dualistas predominam sobre o tema trazendo tons pessimistas e pejorativos as relações informais de emprego. Alguns tratam o setor informal como sendo atrasado e causador de desequilíbrios; outros, como consequências da insuficiência dos mercados tipicamente capitalistas de absorver mão de obra. Os debates iniciais se concentravam na alegação de que, quando há crescimento econômico no país, a informalidade tende a diminuir, gerando mais postos de trabalho no setor formal, porém o tempo mostrou que essa afirmação não é verdadeira, uma vez que, desde os anos 60 a informalidade nas relações de trabalho aumentou, não somente em número, mas em formas.

Oliveira (1988) constrói a crítica ao dualismo, no sentido de que não há oposição entre as duas estruturas do mercado de trabalho e da economia, mostrando que o chamado setor informal, diferentemente das visões anteriores, é próprio das condições de desenvolvimento do capitalismo em países subdesenvolvidos. No caso brasileiro, as condições estruturais capitalistas, mesmo nos setores em que ela é a regra, não processaram a universalização do assalariamento enquanto padrão regular (conferir capitulo 1).

A Organização Internacional do Trabalho apresenta uma definição bastante ampla e objetiva de informalidade, convergindo elementos da ideia de segmentação (setor) e de forma de emprego (vínculo empregatício). Esta categorização rompe com os aspectos de dualismo como já exposto acima e possibilita uma melhor 
compreensão da realidade objetiva do chamado trabalhador informal, principalmente considerando as profundas alterações nas relações de trabalho impingidas com as novas formas legais resultantes da reforma trabalhista. Segundo a OIT as modalidades de inserção no trabalho que se constituem em emprego informal são:

\footnotetext{
trabalhadores por conta própria e empregadores proprietários de unidades produtivas no setor informal, trabalhadores em ajuda a membro do domicílio e assalariados (se a relação de trabalho não está sujeita à legislação trabalhista nacional e à proteção social), membros de cooperativas de produtores informais e trabalhadores que produzem bens prioritariamente para o próprio uso. (OIT, 2003).
}

Como ressaltam Krein e Proni (2010) esta formulação mais ampla "contempla, do ponto de vista metodológico, tanto o critério de unidade produtiva como o de ocupação", possibilitando analisar mais objetivamente realidades que apresentam dinâmicas de informalidade estruturais, como é o caso brasileiro e, inclusive, tratar as alterações econômicas e legais que nas últimas décadas vêm alterando mesmo padrões mais regulares de relações de trabalho, numa perspectiva de flexibilidade tanto contratual, quanto ocupacional dos trabalhadores tipicamente assalariados (DAL ROSSO, 2017), estabelecendo uma segunda geração de informalidade.

\section{ELEMENTOS GERAIS DAS RELAÇÕES DE TRABALHO EM BELÉM}

Segundo o Censo de 2010, o município de Belém concentrava 18,38\% da população estadual, ou seja, 1,3 milhão de habitantes, sendo que desse total aproximadamente $51 \%$ (663 mil) refere-se a população economicamente ativa (PEA), ou seja, a parcela da população acima de 10 anos de idade que está apta ao exercício de qualquer atividade econômica laboral, sendo que a taxa de desemprego, calculada pelos dados do Censo 2010, alcançou a marca de 10,3\%, muito superior aos níveis nacionais e mesmo do estado do Pará, cuja taxa foi de $5,5 \%$ ao nível nacional e de $9,5 \%$ ao nível estadual, para aquele ano. Nas últimas duas décadas a economia da grande Belém apresentou poucas alterações na sua estrutura produtiva, continuou valendo o peso do setor terciário, ou seja, comércio e serviços, e uma baixa integração da microrregião com os projetos instalados no sul e sudeste do estado.

Os esforços de estruturação de uma base produtiva industrial foram bastante tímidos, sendo que os Distritos Industriais de Icoaraci e Ananindeua continuaram 
sua lenta e prolongada implantação, não apresentando dinâmica e estímulo suficiente capaz de alterar o padrão histórico da economia local. Em 1992 as atividades de serviços e comércio detinham $68,8 \%$ da população ocupada, evoluindo para 74\% da mesma em 1999 e atingindo mais de 75\% em 2010, representando aproximadamente 80\% em 2015.

Esses números aparentemente acompanham a tendência de aumento da importância do setor terciário nas economias urbanas brasileiras, contudo às características desse setor refletem mais uma profunda precariedade das condições ocupacionais, próprias de atividades de baixa produtividade e não assalariadas, do que propriamente um terciário moderno vinculado a um alto nível médio de renda per capita. Mesmo considerando a RMB enquanto polo de atração populacional, tendo em conta sua melhor infraestrutura e capacidade de oferta de empregos, contudo os indicadores de renda são demonstrativos de certa perda relativa de importância econômica durante a década.

Deste modo no início dos anos 1990, a grande Belém concentrava 47,79\% da renda estadual, declinando em 1999 para 41,05\% e alcança 35\% em 2014, esses números são estadual, declinando em 1999 para 41,05\% e alcança 35\% em 2014, esses números são decorrentes da implantação e funcionamento dos projetos mínero-metalúrgicos que transformaram o estado do Pará em um grande exportador de minérios, porém com uma baixa capacidade de integração com outros setores da economia estadual e principalmente da região metropolitana.

Os altos níveis de pobreza, baixos patamares salariais, elevados índices de desemprego e subemprego, são acompanhados simultaneamente por um grande nível de concentração de renda, nada distante das próprias características gerais da sociedade brasileira. Na década de 1990 e início dos anos 2000, os dados da PNAD refletiram o recrudescimento da concentração de renda, sendo que o Índice de Gini no final da década de 1990 era de 0,60 , reflexo do fato de que os $1 \%$ mais ricos concentrem $12,0 \%$ da renda metropolitana, enquanto os $50 \%$ mais pobres detinham somente $13,4 \%$ da renda local.

As políticas sociais dos últimos governos nacionais (Lula e Dilma) possibilitaram uma pequena melhora neste quadro, contudo o indicador pouco se modificou, o Índice de Gini passa para 0,61 em 2015, porém a possível interrupção destas políticas com o anunciado retorno dos ajustes neoliberais deve novamente 
recrudescer os indicadores de pobreza. A inserção precária da economia paraense no contexto nacional, baseada na produção de bens primários de baixo valor agregado, fundamentalmente voltado à complementação de cadeias produtivas fora da região, reflete nas condições ocupacionais de Belém.

Ao utilizarmos indicadores de informalidade veremos que ao longo dos últimos quinze anos as relações de informalidade estabelecidas desde a lógica do chamado emprego por conta própria se manteve acima de $27 \%$ da população economicamente ativa ocupada, caracteristicamente precária. Vale ressaltar que durante a atual década houve uma parcial melhora nas estatísticas de emprego e renda formais, acompanhando às estatísticas nacionais, porém o emprego assalariado se mantém estável somente aumentando de $69 \%$ da população ocupada em 2000 para 70\% em 2010. A renda média da população ocupada na capital paraense apresentou uma leve melhora ao longo do período, evoluindo de $R \$ 309,00$ em 2001 para $R \$ 594,00$ em 2009, porém 38,4\% da população ainda vive, segundo o Censo 2010, com rendimento mensal inferior a meio salário mínimo.

Tabela 1 - Participação do trabalho por conta própria sobre o total dos trabalhadores no Brasil, Pará e RM Belém

\begin{tabular}{l|ccc}
\hline Anos & Brasil & Pará & RM Belém \\
\hline $\mathbf{2 0 0 1}$ & 22,31 & 26,6 & 29,05 \\
\hline $\mathbf{2 0 0 2}$ & 22,26 & 26,42 & 28,61 \\
\hline $\mathbf{2 0 0 3}$ & 22,36 & 26,95 & 29,4 \\
\hline $\mathbf{2 0 0 4}$ & 21,98 & 27,27 & 29,95 \\
\hline $\mathbf{2 0 0 5}$ & 21,64 & 26,18 & 27,61 \\
\hline $\mathbf{2 0 0 6}$ & 21,22 & 27,55 & 30,45 \\
\hline $\mathbf{2 0 0 7}$ & 21,19 & 27,07 & 26,51 \\
\hline $\mathbf{2 0 0 8}$ & 20,24 & 27,43 & 27,99 \\
\hline $\mathbf{2 0 0 9}$ & 20,48 & 28,18 & 28,45 \\
\hline $\mathbf{2 0 1 1}$ & 21,02 & 30,34 & 28,49 \\
\hline $\mathbf{2 0 1 2}$ & 20,64 & 30,25 & 28,97 \\
\hline $\mathbf{2 0 1 3}$ & 20,61 & 29,17 & 27,01 \\
\hline $\mathbf{2 0 1 4}$ & 21,29 & 30,2 & 29,85 \\
\hline $\mathbf{2 0 1 5}$ & 22,88 & 32,08 & 31,61 \\
\hline
\end{tabular}

Fonte: PNAD/ IBGE. Elaboração própria. Nota: taxa de participação do trabalho autônomo sobre o total de trabalhadores. Trabalho autônomo e por conta própria são uma mesma categoria de ocupação.

Este quadro de baixa renda se reflete em outros aspectos, como por exemplo, a elevada carga horária de trabalho diária, necessária para suprir o mínimo de renda necessário a sobrevivência. Segundo a Pesquisa Nacional de Amostragem 
Domiciliar (PNAD), em 2015, mais de 65\% da população ocupada trabalhava acima das 40 horas semanais, sendo que mais de 15\% da população ocupada em Belém tinha que trabalhar mais que 50 horas semanais para poder obter o mínimo de renda necessária.

Tabela 2 - Pessoas de 14 anos ou mais de idade, ocupadas na semana de referência, por posição na ocupação no trabalho principal - $3^{\circ}$ Trimestre 2018 (em \%)

\begin{tabular}{lccccc}
\hline & \multicolumn{5}{c}{ Posição na ocupação no trabalho principal } \\
\cline { 2 - 6 } & Total & Empregado & Empregador & $\begin{array}{c}\text { Conta } \\
\text { própria }\end{array}$ & $\begin{array}{c}\text { Trabalhador } \\
\text { familiar } \\
\text { auxiliar }\end{array}$ \\
\hline Brasil & 100 & 67,5 & 4,8 & 25,4 & 2,4 \\
\hline Pará & 100 & 55,8 & 4,3 & 34,6 & 5,3 \\
\hline $\begin{array}{l}\text { Região Metropolitana } \\
\text { Belém (PA) }\end{array}$ & 100 & 62 & 3,5 & 32,8 & 1,7 \\
\hline Fonte: IBGE (PNAD-C), 3º & Trimestre 2018. Acessível em: https://sidra.ibge.gov.br/home/pnadct/para
\end{tabular}

A noção de autônomo do IBGE (PNAD) enquanto todo aquele de trabalhador que exerce sua atividade profissional sem vínculo empregatício, por conta própria e com assunção de seus próprios riscos, abrange os trabalhadores aqui analisados, sendo que no terceiro trimestre de $2018,32,8 \%$ das pessoas de 14 anos ou mais de idade, ocupadas na semana de referência na RMB, por posição na ocupação no trabalho principal faziam parte deste contingente da força de trabalho. Vale notar, ainda, que a Construção Civil, ainda segundo os dados do IBGE (PNAD-C) representa quase $7,5 \%$ da população ocupada acima de 14 anos brasileira e paraense.

Tabela 3 - Pessoas de 14 anos ou mais de idade, ocupadas na semana de referência, por grupamento de atividades no trabalho principal $-3^{\circ}$ Trimestre 2018 (em \%)

\begin{tabular}{|c|c|c|c|c|c|c|c|c|c|c|c|}
\hline & $\begin{array}{l}\frac{\pi}{3} \\
\frac{2}{3} \\
\frac{0}{2} \\
\frac{0}{4}\end{array}$ & 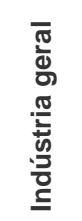 & 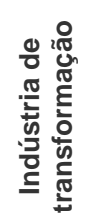 & 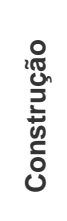 & 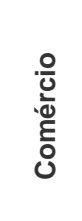 & 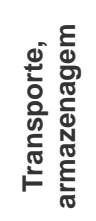 & 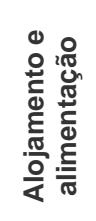 & 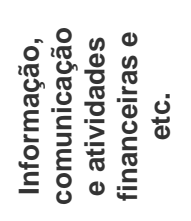 & 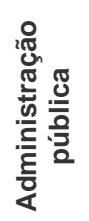 & 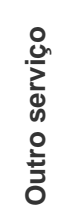 & 这 \\
\hline Brasil & 9,4 & 12,8 & 11,5 & 7,3 & 18,9 & 5 & 5,8 & 11 & 17,6 & 5,3 & 6,8 \\
\hline Pará & 16,2 & 11,5 & 10 & 7,3 & 21,5 & 4,8 & 5,6 & 4,9 & 17,4 & 4,8 & 6,1 \\
\hline
\end{tabular}

Fonte: IBGE (PNAD-C), $3^{\circ}$ Trimestre 2018. Acessível em: https://sidra.ibge.gov.br/home/pnadct/para 


\section{O PERFIL SOCIOECONÔMICO DOS TRABALHADORES E DE SUAS FAMÍLIAS: TRAJETÓRIA DE VIDA E DE TRABALHO DOS ATORES ENTREVISTADOS}

Os três atores entrevistados têm como origem municípios interioranos em relação a Região Metropolitana de Belém, sendo que suas famílias se deslocaram das referidas localidades nas décadas de 1970 e 1980, período de forte fluxo migratório para Belém. Convém aqui uma breve digressão sobre o processo migratório para Belém nas décadas recentes. Os principais vetores do processo migratório foram, de um lado a desorganização da forma de vida ribeirinha principalmente decorrente da implantação de grandes projetos de exploração mineral ou agropecuário no hinterland paraense, por outro, a incapacidade das pequenas e médias cidades paraenses e, em geral, brasileiras, de possibilitar infraestrutura básica e garantia de renda mínima para sua população, o que levou a ciclos permanentes de expulsão populacional rumo a RMB (Região Metropolitana de Belém).

Para analise estabelecemos uma padronização da informalidade: i) o que denominamos de informal regular tem como característica central a permanência continua na informalidade não tendo, por diversas razões, interesse de estabelecer padrões contratuais mais regulares, mais fixos ou num sistema de contratação plenamente subordinada; ii) o informal não regular, cuja característica principal relaciona-se ao ciclo de entrada e saída da formalidade ou certo padrão contratual que o trabalhador busca se inserir, porém com crescente dificuldade e com decrescentes garantias ou direitos; iii) por fim, identificamos um padrão de informalidade centrado na ideologia de mérito pessoal, ou seja, uma percepção que condiciona suas rotinas e condições de emprego e renda a pretensa capacidade pessoal de exercício das atividades. Essa condicionalidade ideológica parece ser crescente na sociedade brasileira e o trabalhador objeto de análise reflete perfeitamente o discurso de meritocracia.

\subsection{O INFORMAL REGULAR}

O primeiro entrevistado Antônio é natural do município de Irituia - Região de Integração do Rio Capim - Pará, nascido em 1975, sendo o filho mais velho de três irmãos. Sua família migrou para Belém na procura de melhores condições de vida. 
Relata que aos 10 anos começou a trabalhar e esclarece que, quando tinha essa idade, seu pai, também pedreiro, "tirando um bico" sofreu um acidente: "foi limpar o poço, tirar umas casquinhas de madeira, que era para colocar uns tubos de concreto [...] a talha saiu, caiu aqui em baixo, essa talha veio e bateu na cabeça dele [...] desconjuntou a coluna [...] ele veio a óbito".

Com a ausência do pai, o entrevistado passou a ter papel importante na família, passou a zelar pelos seus irmãos quando a mãe saia para trabalhar. Passou a vender picolé, banana, farinha, e algumas vezes ainda tentava pescar em rio nas proximidades de sua casa. Completando 14 anos "tirava uns bicos" na construção civil "batendo massa, carregava tijolos", como ajudante de pedreiro, tudo que recebia dividia com a sua mãe.

A mãe de Antônio tinha escolaridade fundamental, assim como seu pai, porém sabia costurar. Quando perdeu o esposo, fez um curso de enfermagem, mas não trabalhou na área. Se inserido de fato no ramo de corte e costura, até o momento em que pensão foi liberada, na época o pai de Antônio, trabalhava de carteira assinada, por isso a concessão do direito. Com 17 anos conheceu sua esposa, que tinha somente 15 anos e que também migrou com a família em busca de melhores condições, vinda do estado do Maranhão. Pensativo, explica que logo 0 namoro se tornou casamento, devido ao abandono família que na época sua esposa sofreu com três irmãos pequenos. Ao falar desse episódio, lembra que a esposa trabalhava em casa de família, mas pediu demissão para cuidar dos irmãos, e Antônio, passou a dividir metade das diárias de pedreiro entre a casa da mãe e o novo lar, e segue casado há 30 anos. Na época os irmãos de sua esposa tinham 07 , 10 e 13 anos. "todos já trabalharam comigo, já levei para trabalhar todos comigo". Conta que hoje "um deles exerce atividade de mecânico, outro é carreteiro, mas está atuando somente como mecânico, porém faz bicos na construção civil".

Comenta que por esse motivo estudou somente até a oitava série, justamente devido ao trabalho, "trabalhava, aí para chegar 6,7 horas da noite, e já sair correndo, [...] eu tinha 26, 27 [anos], foi que conclui, fiz sétima e oitava, quase que não concluo, fica muito cansativo trabalhar em tempo aberto, sol quente, ai eu passei e parei, estava muito cansativo para mim, os filhos tudo pequeno, mulher, na época era difícil de morar alugado [...] morei em uma casa só e não deu certo, ai eu fui morar alugado, ai sai do aluguel fui morar com a minha mãe e não deu certo, meu 
padrasto batia de frente com a minha esposa, larguei fui morar em um lugar de novo, até que eu fiz uma casa com a minha irmã, ela me deu as madeiras, eu fiz uma de madeira para mim, e construí uma de alvenaria do lado". Sua esposa na época também abandonou os estudos, aos 20 anos voltou, concluindo o ensino médio, na tentativa de fazer um curso técnico de enfermagem não teve êxito abandonou três vezes devido a mensalidade. Início depois de um tempo o curso superior de Administração, também trancou, atualmente estuda Serviço Social.

Até uns meses atrás, uma parte do bairro Castanheira, onde mora Antônio, era considerado "invasão", recentemente devido a urbanização, houve a regularização dos lotes, da energia, porém o saneamento básico ainda é precário, e poucas linhas de ônibus circulam no seu interior, tem de se descer na BR 316 e ir caminhando.

Enquanto que Antônio começou a trabalhar com 10 anos de idade, seu irmão iniciou apenas com 15 anos, indo trabalhar com o esposo de sua irmã que casou cedo, “ (...) ele levou ele para lá, começou a ensinar..., e hoje em dia ... é mecânico...”. Diz que faz apenas 4/5 anos que a irmã começou a trabalhar em uma pousada, ganha um salário mínimo, com carteira assinada, antes só cuidava dos filhos e da casa. Se tratando no núcleo familiar de sua irmã, diz que sua sobrinha trabalha em uma pousada, porém recebe por quinzena e é informal. O esposo da sobrinha é mecânico borracheiro, trabalha em uma oficina de carros pelas redondezas. Não comentou sob a configuração da família do outro irmão.

Antônio tem hoje aproximadamente 43 anos, sendo que há 28 anos trabalha na construção civil, sendo sua aprendizagem toda no exercício do ofício: “(...) comecei como ajudante, em um ano e pouco, já fui para meio oficial, já sabia fazer alguma coisa, reformar, rebocar, levantar uma alvenaria, aí já foi começando, fiquei profissional, já fazia tudo, rebocava, levantava, fazia telhado, serragem, tudo, fundação [...] sou pedreiro, sou carpinteiro, sou terreiro, sou pintor, parte de eletricidade, eu faço só baixa".

A aprendizagem no próprio serviço é a tônica da construção civil no Brasil, sendo que a baixa tecnicidade do segmento e mais especificamente das obras realizadas por trabalhadores informais (empreitadas de baixa escala), estabelece um ponto importante de diferenciação entre os trabalhadores. Neste caso, o entrevistado enaltece sua habilidade, o que possibilita sua maior empregabilidade frente a outros trabalhadores. 
Fala reiteradamente que não acha seu trabalho desvantajoso, sempre paga melhor que com carteira, "eu tiro 3.000, 4.000". Vale analisar que o caso deste trabalhador sinaliza o quanto o grau de precariedade na chamada formalidade estabelece uma contraditória vantagem para alguns trabalhadores que, tais como o caso analisado, apresenta habilidade acima da média, facilitando aparentemente sua empregabilidade.

\subsection{O INFORMAL NÃO REGULAR}

A trajetória e perfil socioeconômico do segundo entrevistado tem um panorama inicial bastante semelhante ao anterior, José migrou com a família ainda com oito anos do município de Porto de Moz localizado no sudoeste paraense. Inicia suas atividades laborais muito cedo, ainda com doze anos passa a trabalhar como ajudante de pedreiro com seu avô. Neste caso também temos o processo habitual de aprendizagem no próprio ofício, que como fala o entrevistado implicava em aprender um pouco de tudo: "(...) eu ia para um lado, ia para outro, trabalhando na parte de carpintaria, na parte de hidráulica, parte de gesso, parte de pintura, aí eu fui trabalhando, fui aprendendo as profissões também junto com os profissionais $(\ldots)$..

José tem 32 anos e mora em bairro da periferia de Belém, ocupação relativamente recente, do final dos anos 1990, o bairro do Aura, sem saneamento e pouca infraestrutura. A educação formal do entrevistado também foi bastante precária, fez até a quarta séria primária, resultante da necessidade como se refere da opção pela sobrevivência: (...) tinha que optar, ou trabalhava ou estudava e aí eu preferi trabalhar na época".

Os rendimentos médios de José são inferiores ao nosso primeiro entrevistado, sendo que sua condição de informalidade nos parece levar a um grau de vulnerabilidade maior que o primeiro, o que se faz notar pela condição recente do mesmo ter que trabalhar como "flanelinha" ou tomador de conta de carros em estacionamento aberto. A renda média estaria em torno de $R \$ 700,00$ semanais, sendo variável, como observa na entrevista: “(...) esse período de 2014 lá até 2016 eu ganhava $R \$ 500,00$ ou 600,00 , ai de 2016 para cá para 2018 foi aumentando... 
$\mathrm{R} \$ 800,00$, e tinha a semana que nem mesmo, porque não tem serviço grande tirava $\mathrm{R} \$$ 400,00 (...)".

A trajetória de ocupação deste ator também é diferente do primeiro, sendo que nos últimos quinze anos, esteve várias vezes empregado formalmente, sendo sua interação com o mercado de trabalho algo marcado pela chamada condição do "fichar", ou seja, a procura por uma empresa em que possa se estabelecer e exercer suas atividades laborais.

A hipótese aqui levantada é que parcela dos trabalhadores informais presentes na atual crise econômica estabeleceram algum grau de vinculação com elementos de "estabilidade" próprias do sistema de emprego celetista na última década e que parece ainda ter influência no comportamento dos mesmos, assim este trabalhador observa que “ (...) eles [a empresa] me deram a oportunidade, ai eu segurei a oportunidade porque me ficharam lá como manutencionista e botaram na minha carteira como pedreiro, de lá que eu já fui trabalhando e até hoje na minha carteira, estou agora empregado de novo, Graças a Deus, e é como pedreiro (...)". Estamos, portanto, lidando com um "informal não-regular", que definiríamos como sendo trabalhadores que encaram a condição da informalidade enquanto um padrão mais inseguro e que buscam, de alguma forma, certa guarita em padrões de emprego mais formais ou, pelo menos, assegurados pela relação empresarial.

\subsection{A INFORMALIDADE REGULAR E A IDEOLOGIA DE MÉRITO PESSOAL}

O terceiro entrevistado, João, apresenta algumas características distintas dos demais, por mais que os aspectos gerais de precariedade e inseguranças sociais e econômicas se manifestem enquanto vetor comum aos demais. Neste caso o trabalhador em tela tem origem na própria cidade de Belém, apresentando um perfil de escolaridade melhor que os demais. Estudou formalmente até o segundo ano do segundo grau (onze anos) e apresenta menor instabilidade no seu padrão médio de renda, como veremos com a sua exposição.

João começou a trabalhar com 16 anos e também a exemplo dos demais teve sua aprendizagem laboral resultante do próprio "aprender fazendo". O entrevistado é o mais velho dos três trabalhadores envolvidos na pesquisa, tem 44 anos e apresenta maior desprendimento na busca de oportunidades, bem como manifesta maior determinação pessoal. Os rendimentos médios de João oscilam conforme a 
carga de trabalho obtida, mas segundo ele " (...) se eu trabalhar mais de um mês numa mesma obra, durante o mês dá para tirar uns $\mathrm{R} \$ 2.000,00, \mathrm{R} \$ 2.500,00$ (...)".

O discurso de João se estabelece em torno de uma visão de mérito pessoal, sendo que na sua fala se revela, de um lado, um forte individualismo, centrado na percepção do esforço pessoal, de outro uma enorme descrença nas instituições, inclusive sindicatos, como exporemos mais a frente, assim ele se considera “ (...) um profissional (...) bastante rápido. Então eu sou aquele profissional que [não] enrola serviço (...). Tanto que todas as firmas que eu fui ou o encarregado ou o engenheiro pediram para mim não sair, por quê? Porque eu sempre fui um bom profissional. $E$ hoje eu tenho a minha profissão porque eu gosto de trabalhar (...)".

Consideramos que estamos diante de um trabalhador cuja característica social e econômica seria de um tipo de informalidade mais estrutural, existente independente do ciclo econômico dito formal e que ao deter determinadas características ou habilidades pessoais assimila muito facilmente um discurso de mérito, por mais que os fatores de insegurança permaneçam.

\section{O MUNDO DO TRABALHO INFORMAL: A TRAJETÓRIA OCUPACIONAL DO TRABALHADOR NO TEMPO E NO ESPAÇO}

\subsection{A TRAJETÓRIA OCUPACIONAL DO INFORMAL REGULAR}

Antônio relata que teve poucas experiências com vinculo celetista. Trabalhou na Construtora ESTACOM, uma grande empreiteira, sempre associada a obras públicas, nos projetos da Companhia de Habitação do Estado do Pará e Secretaria de Obras e Planejamento. Trabalhou em um cenário de crise da construção civil: "não estava deixando ninguém trabalhar muito tempo, assinavam um contrato, 3 meses, então assinava mais 3 , desses três meses quando você chegava automaticamente nos teus 88 dias, ele já te dava o teu aviso".

Trabalhou ainda na Global empresa que prestava serviços para a igreja Universal, em torno de um ano, em um hospital privado, como em todo lugar que se trabalha com obra, diz que recebia somente o salário de $R \$ 1.300,00$ e caso não houvesse faltas em seu ponto, havia um bônus de $R$ \$ 50,00 reais. Explica que nas empresas de construção civil não existe nada que de "vantagem", não há, vale refeição, plano de saúde, qualquer benefício não existe até mesmo o vale 
transporte, por isso muitos trabalhadores vão e voltam do trabalho de bicicleta. Exclama, "é bem comum voltarmos para casa e ver um colega no acostamento [atropelamento], sempre há acidentes, é de noite e o cansaço aparece”.

Destaca que quando trabalhando com carteira assinada, por conta do baixo salário, sempre aos finais de semana, estava trabalhando, para complementar a renda, "a gente faz, quando chega final de semana lá em casa, nas minhas folgas, faço um bico por fora". Comentou, ainda, que não via "vantagem" alguma em ter a carteira assinada, afirma que ao fraturar a coluna quando trabalhava na ESTACOM, trabalhou mais três meses, mas no quarto mês, entrou de benefício, relata o acidente: “ (...) fiquei uns 3 meses, aí fiz a primeira perícia e na segunda eu estava com as pernas inchadas, mãos inchadas, eu nem conseguia andar direito e o médico disse que eu tinha que voltar a trabalhar que aquilo era moleza minha, que eu estava com o meu corpo mole, eu voltei chorando de raiva, ele mandou eu bater uma chapa, só que em chapa não atesta nada, tinha que ser ressonância, aí eu fui e levei a chapa e ele disse que não tinha nada não que estava fazendo corpo mole que tinha que voltar a trabalhar, eu andava assim, se eu tivesse apto para trabalhar eu nem iria para o hospital".

$\mathrm{Na}$ trajetória mais recente do entrevistado, há um ano aproximadamente, esteve trabalhando na cidade de Fortaleza, "encostado, trabalhei lá em uma obra, levantando vila de casa de três andares, dois apartamentos, cheguei lá não conhecia ninguém, comecei, ai o rapaz falou você sabe fazer fundação, você quer vaga para ajudante, eu trabalhei duas semanas lá como ajudante, tirava 50 reais a diária para poder ficar no serviço, cavando a fundação, ajeitando o pessoal lá, ai depois eu fui passar para pedreiro, comecei a levantar, trabalha bem, trabalha rápido, vai ficar, vai lá, só que aí veio me pagar 80 reais a diária no avulso".

Claramente expõe que esses não são os anos de ouro da construção civil, a realidade é que o setor está em crise nacionalmente, sendo que o preço da força de trabalho está em declínio. Comenta que o desemprego é grande, e que antes o que era serviço de "peão" passou a ser trabalho para pessoas que possuem nível superior. Nesse período tinha despesas em torno de $R \$ 1.300,00$ reais e ganhava aproximadamente 1.800,00. Sua esposa também trabalhou "avulso" em uma padaria, porém ficou doente, tendo que ausentar-se. Igualmente, trabalhou em fábrica de calcinha por produção, porém se ausentou mais uma vez devido a 
problemas respiratórios. Comenta que a remuneração entre Belém e Fortaleza é bem similar, "tudo é questão de negociação e conhecimento".

Sobre sua rotina de trabalho disse, que sempre trabalhou em média 10 horas por dia, há tempos que trabalha 14 horas, e outros 8horas. Os menores tempos de trabalho decorrem de serem prédios, devido os horários que não é permitido fazer barulho. Apesar da jornada de trabalho ser intensa, Antônio, fala que não deseja ser empregado de carteira assinada.

Diz que quase nunca ficou sem trabalho para fazer, todo tempo é acionado, nunca lhe faltam clientes, porque cumpre com seu trabalho. Até mesmo no inverno, tempo em que os serviços quase ficam escassos devido a as chuvas, sempre tem uma "obrinha, um reboco, um acabamento" [...] às vezes aparece para fazer por fora, mas modifica, a gente trabalha quatro dias na semana porque chove muito, de manhã a gente trabalha até às duas horas e de tarde é chuva, às vezes amanhece chovendo e vai até meio dia trabalhando só até à tarde, o material tem que estar tudo encapado. Mas sabendo disso, todo mês reserva um pouco de sua renda, para se manter nesses meses.

Os relatos de Antônio nos levam a deduzir que houve certa deterioração das suas condições de vida nos últimos três anos, o que o levou inclusive a tentar a vida em Fortaleza. Em Fortaleza suas condições de vida foram difíceis, como relata: “ (...) [o] pessoal sabendo como eu não era de lá, era de Belém, e precisa[va] trabalhar, que morava alugado, eles pegavam e não pagavam a diária, a mão-diária de 100 reais, 120, eu trabalhei duas semanas lá como ajudante, para poder ficar no serviço, cavando a fundação, ajeitando o pessoal lá, ai depois eu fui passar para pedreiro, ah vamos fazer uns testes, não encontrei ninguém ainda que passasse no seu teste de alvenaria, comecei a levantar, trabalha bem, trabalha rápido, vai ficar, vai lá, só que aí veio me pagar 80 reais a diária".

Em termos teóricos e analíticos podemos afirmar que seis fatores influenciam as condições de sobrevivência e a trajetória ocupacional do trabalhador informal: i) os ciclos econômicos e sua maior ou menor duração recessiva em termos de impacto na construção civil; ii) a habilidade do trabalhador informal, o que possibilita uma maior ou menor duração em tempo de ocupação; iii) sua rede de contatos; iv) condições materiais ou propriedade sobre meios de produção básicos, fator importante de diferenciação entre trabalhadores e de capacidade de mobilização de 
ajudantes; v) características de personalidade que possibilitam alargar a referida rede de contato e; vi) os vínculos familiares.

O trabalhador que estamos denominando de Informal Regular apresenta a característica de ser pouco condicionado às alterações no ciclo econômico, sendo que fatores como habilidade, rede de contatos e família são elementos mais importantes nas condições de reprodução social e econômica do mesmo. Uma investigação mais aprofundada sobre as condições de apropriação de excedente econômico que possibilite adquirir alguns meios de produção básicos ou mais estruturantes nos parece aspecto importante no aprofundamento da pesquisa.

\subsection{A TRAJETÓRIA OCUPACIONAL DO INFORMAL NÃO REGULAR}

José tem uma trajetória fortemente marcada pelos vínculos formais, já se empregou em três empresas (Plastbel, Cropólis e Elecnor). Estes trabalhadores informais são resultantes do último ciclo de crescimento econômico que, como ele descreve, estabeleceu uma forte marca de identidade, assim ele afirma: "(...) com 18 anos arrumei emprego, tive, então, já assim como um profissional, mas não de carteira assinada, aí tive a oportunidade me empregar numa época, estive empregado em várias empresas e ai chegou numa, quando eu cheguei lá e falei para eles o que eu sabia fazer, trabalhava de pedreiro, trabalhava com o negócio de pintura, trabalhava na parte de gesso, ai eles fizeram um teste comigo, nessa empresa PLASTIBEL, e lá eles me deram a oportunidade, ai eu segurei a oportunidade porque me ficharam lá como manutencionista e botaram na minha carteira como pedreiro, de lá que eu já fui trabalhando e até hoje na minha carteira, estou agora empregado de novo, Graças a Deus, e é como pedreiro". Nosso ator tem uma forte característica de instabilidade pessoal, demonstrada nas relações pessoais que relata, o que dificulta seu processo de transição entre uma ocupação e outra e o torna bastante dependente da necessidade de formalizar seus vínculos empregatícios.

Como ele mesmo observa: “(...) de 2014 até aqui, até agora em 2018, eu fiquei trabalhando informalmente, aí eu construí duas casas (...) sempre fiquei trabalhando (...). Ai agora esse período agora desse mês de outubro de 2018 eu me empreguei numa obra que a gente estamos fazendo (...) me registrei como pedreiro, sou empregado agora novamente, Graças a Deus, e eu estou na expectativa ai de 
poder me encaixar lá no quadro de funcionário e ter uma boa relação como eu tive nas outras empresas e seguir em frete (...)".

Temos com João um quadro diferente na relação formal (empregado em empresa) e informal, o que sugere que oscilações cíclicas na economia ainda sejam um fator importante no comportamento dos trabalhadores informais, inclusive condicionando sua menor ou maior aderência a um comportamento mais empreendedor, inclusive adquirindo meios de produção ou formatando redes de contato mais organizadas com vistas a obtenção de clientes.

\subsection{PERCEPÇÕES, PERSPECTIVAS E POSICIONAMENTOS POLÍTICOS DOS ENTREVISTADOS}

Os entrevistados desenvolvem percepções não muito diferenciadas em relação aos últimos governos, sendo que mesmo tendo uma visão de melhoria no período dos governos Lula/Dilma, porém dois deles estabelecem forte oposição aos governos e manifestam uma forte contradição quanto ao significado dos mesmos. A visão preponderante refere-se às condições de melhores de oferta de emprego e ganhos salariais, mesmo que também prepondere uma visão negativa quanto ao aspecto corrupção. Vale analisar que os fatores que determinariam visões tão dispares podem estar relacionadas ao sentimento consolidado no processo eleitoral, porém estabelecido antes do mesmo, quanto ao caráter dos respectivos governos.

O entrevistado José, que manifesta grande simpatia por Lula, observa que "muita gente fala que o Lula fez isso, fez aquilo, e o primeiro emprego na minha vida foi quando o Lula ganhou, nessa época eu tinha, estava com meus 19 anos, foi meu primeiro emprego, trabalhei numa empresa chamada JS Construtores, foi o Lula que fez aquele projeto Luz no Campo, que eu posso dizer que, tem gente que diz que ele não fez nada, mas na minha opinião ele fez porque se roubou, ele roubou, mas pelo menos eu sei que ele fez algo". A marca mais evidente no discurso refere-se às condições de geração de emprego do período, que tornaram os dois governos Lula um momento de parcial ruptura com as trajetórias de informalidade, pois se alcança neste período as maiores taxas de formalização do mercado de trabalho (XX\% em $X X)$. Por outro, a tônica do discurso da mídia penetra o imaginário de José ao expressar que Lula teria "roubado". 
Convém analisar o segundo discurso, de Antônio, segundo ele o governo Lula “...foi melhor, teve mais emprego, mais na construção civil que aumentou, mas quando chegou para Dilma já diminuiu, aí quando foi o Temer piorou". Porém, este ator parece mais influenciado pelo discurso midiático que o primeiro, sendo que sua percepção quanto ao caráter de descontinuidade dos governos do PT são muito fortes, para ele, por mais que o movimento de retirada da presidenta Dilma do governo tenha sido golpe, porém o processo todo teria sido consequência da transição ruim entre Lula e Dilma, o que expressa nos seguintes termos: “ (...)acho que foi um golpe, o Lula fez tudo, pagou as dívidas externas, aí ficou lá em cima, aí pegou abacaxi para a Dilma, passou os 8 anos dele saiu e jogou para a Dilma e a Dilma ficou com o rombo, ele meteu a mão e o povo achou que ele fez tanto e jogou bomba para ela, tanto é que hoje em dia você está pagando mais caro a sua energia porque aumentou energia e até 2020 ou 2025 você vai pagar energia mais cara porque ela ficou devendo milhões e milhões para a concessionária de energia, ela não zerou a conta dela e o que acontece ela distribui para a população então todo trabalhador tem que pagar aquela taxa máxima para cobrir o rombo que ela deixou".

A visão diferente entre José e Antônio se expressa na votação para presidente em 2018, o primeiro votou Haddad e o segundo Bolsonaro. Considerando a conformação econômica semelhante, convém problematizar como se formou a compreensão de cada um sobre os governos petistas.

Antônio expressa que votaria em Bolsonaro mesmo sendo Lula candidato, esclarece que sua opinião seria decorrente de uma visão de segurança individual: “...eu sempre fui a favor de você se defender, essa lei que eles fizeram aí eu sou contra [legislação da maior idade penal], como eu lhe falei comecei a trabalhar cedo, perdi o meu pai com 10 anos de idade, sempre comecei trabalhar cedo, fazia alguma coisa errada minha mãe me batia, não morri, trabalhei cedo pra caramba, não sou ladrão, não sou nada e tenho minha profissão".

O discurso simplório em torno de a segurança pública ser resolvida a partir de autoproteção (tese do fim do Estatuto do Desarmamento) parece estar na base da diferença entre os dois atores analisados. Elementos de conservadorismo também aparecem na construção do discurso de um e outro enquanto pontos importantes.

Convém observar uma terceira linha de discurso, o que é externado pelo terceiro entrevistado "João", ao longo da entrevista transparece um elevado grau de descrença em todas as instituições e se coloca numa percepção de impossibilidade 
de solução dos problemas pelas vias convencionais (eleitorais), segundo ele: “(...) vou the dizer uma coisa, eu votei para Lula, votei para Dilma e não vou votar de novo, vou votar em branco".

Essa visão de descrédito se estabelece desde um conjunto de entendimentos que parece se construir ao longo da trajetória e da forma de viver e reproduzir suas condições de vida, assim 0 ator em questão parece ser um tipo próprio de informalidade, detém uma certa especialização e algum nível de propriedade sobre meios de produção, o que o definiria como "autônomo" propriamente dito, o que se expressa na sua fala: "...trabalho para muito tipo de pessoa, trabalho para 0 , até para a dona de casa, faço trabalho até, até para doméstica eu faço trabalho. Trabalhos pequenos, claro, não é como trabalhar com empresário. Mas eu tenho muitos empresários que eu trabalho também. Obras grandes". A fala expressa certo grau de autonomia em relação aos outros dois atores que, assim parece, apresentam maior grau de precariedade.

O discurso autônomo também se reflete na percepção política do ator, sendo que seu descrédito nas decisões eleitorais curiosamente não são resultado de perdas ou não ganhos ao longo dos governos petistas. Exemplos são vários na entrevista, desde o acesso da filha mais velha a universidade pública (UFPA, curso de odontologia) e a obtenção de casa própria (Minha Casa Minha Vida), porém se construiu na percepção do ator uma visão "meritocrática" expressa em falas como [acerca da informalidade]: " não é por opção que eu estou trabalhando por conta própria, é porque eu gosto. Eu me sentia muito lesado quando eu trabalhava de carteira assinada E por que me sentia muito lesado? Eu sou um profissional que eu trabalho bastante rápido. Então eu sou aquele profissional que enrola serviço, então eu me sentia lesado. Tanto que todas as firmas que eu fui ou o encarregado ou o engenheiro pediram para mim não sair, por quê? Porque eu sempre fui um bom profissional. E hoje eu tenho a minha profissão porque eu gosto de trabalhar".

Analiticamente temos nos três discursos elementos importantes para compreensão da interatividade entre a informalidade e a percepção política que se formou. No discurso de José, caracteristicamente uma informalidade estabelecida desde um processo de refluxo do ciclo econômico, pois o mesmo trabalhou várias vezes nos últimos 15 anos com carteira assinada e guarda forte memória dos ganhos obtidos no período Lula, principalmente por conta que coincide com sua 
juventude e primeiro emprego (tem 32 anos e obteve o primeiro emprego - formal com 18 anos).

Podemos afirmar que o caso de José corresponde a uma parcela da informalidade que se estabelece com a crise econômica de 2014, segundo o ator: “(...) de lá para cá, de 2014 até aqui, até agora em 2018, eu fiquei trabalhando informalmente, ai eu construí duas casas, uma de 60 metros quadrados, e construí uma de 160 metros quadrados, ai o resto dessas casas que eu peguei foi reformas que eu peguei, pintura, assentamento de lajotas, assentamento de porcelanato, ai sempre tem que fazer, ai fiquei trabalhando de lá para cá, fazendo muita coisa, sempre fiquei trabalhando, nunca parei, eu sempre tive meus clientes, ai às vezes, a pessoa me ligava para fazer um servicinho, vou trocar uma porta, uma fechadura, fazer acabamento, eu ia fazer, sempre fiz". Esse segmento de trabalhadores informais guarda memória positiva dos governos petistas e apresentam um posicionamento em termos de futuro ainda bastante otimista, provavelmente em função de uma esperada mudança no quadro conjuntural que os leve a retomar condições de vida perdidas muito recentemente.

O segundo entrevistado, Antônio, pode ser analisado como tendo um comportamento social e econômico de um conta própria não totalmente desprovido de meios de produção, dependendo da oferta de trabalho também sazonal, a exemplo de José, porém com maior grau de autonomia e expertise, o que o faz ser um "contratador" de outros trabalhadores informais. O aspecto político deste ator é uma configuração mais conservadora, como se depreende da fala sobre o sindicato: “(...)o sindicato ele só é bom para fazer greve, para fazer bagunça, repassa e chegar e te motivar a fazer greve, chegar lá e apoiar para sair na rua, mas chega lá com isso, aquilo, para falar a verdade às vezes que eu trabalhei nunca fui no sindicato para pegar um atestado, nada, nunca precisei, é descontado lá uma quantia, mas nunca precisei do sindicato, quando precisei ir lá não tinha médico aí fui para o SUS, SUS você morre e não acontece nada, última vez que eu fui era para bater uma chapa (...)". Esse tipo de ator foi aquele ganho para o tema da segurança conforme a percepção da direita, por mais que tenham votado no PT nas últimas quatro eleições.

Por último, temos a compreensão de João, como já frisado, seu posicionamento político, bem como visão de futuro, parece ser muito mais independente que os demais. Podemos aludir a hipótese que estes segmentos da 
informalidade compõem historicamente a grande massa de eleitores que se abstém ou anulam seus votos. O perfil sob o ponto de vista mais amplo constitui uma posição menos conservadora em geral do que o tipo 2 (Antônio), principalmente em aspectos como garantia de cidadania, porém apresentam uma visão mais dura da realidade: “(...) já passei por muita dificuldade na minha vida, e eu vejo que, aí a gente lembra, né? Sabe como é ter um filho, casal de filho e muita das vezes não ter um alimento digno na mesa. As pessoas, ah, mas tem feijão com ovo. Feijão com ovo todo dia ele não é uma comida digna. E eu acredito que, sei lá, é muito triste, um país como o nosso, rico em muitas coisas, muita gente passando fome, necessidade.

Vale notar que nos três casos analisados, a diferença quanto a necessidade de contribuir para o INSS com vistas a aposentadoria parece se estabelecer em duas visões. José entende a necessidade de contribuir e apresenta uma visão mais preocupada com o futuro, enquanto os demais não contribuem regularmente para a previdência e apresentam uma elevada despreocupação com o futuro, porém nos três casos observa-se um forte grau de insegurança futura.

José observa que “(...) pelo período que eu passei lá atrás, porque já tinha passado por muitas situações lá atrás, mas nunca tinha passado por esse período de eu, eu era uma pessoas assim, eu sou um pedreiro que repara casas, ficava pensando nisso, hoje em dia eu penso assim, de construir algo, agora que eu trabalho de carteira assinada, deixei de trabalhar de flanelinha, vou trabalhar de carteira assinada, não penso em nenhum momento de deixar de contribuir com o sindicato, com o INSS, porque sei que isso vai ser um seguro, vai ser um benefício para o resto da minha vida, e assim, pretendo poder hoje em dia abrir algo para mim também, se no caso não ficar lá, mas um dia eu vou sair da empresa, se eu sair, se for trabalhar para mim, tem que contribuir com o INSS, porque a única coisa que eu vou ter, se acontecer algo comigo eu sei que vou estar respaldado, não é?" A interpretação quanto a necessidade de manter a contribuição ao INSS parece estar vinculada ao aprendizado ganho no período em que esteve vinculado formalmente a alguma empresa.

Antônio, por outro, tem uma visão muito individualista e centrada numa preocupação de curto prazo: “(...) penso assim que, eu estou trabalhando encostado, o que acontece, minha esposa está trabalhando, meus filhos estão se 
formando, a casa que eu fiz lá, ela tem dez metros e cinquenta de cumprimento, 50de largura, fiz uma fundação boa, levantei a minha laje, pelo menos foi levantando a cima, fazer uma casa em cima, e em baixo botar ponto comercial, para me manter, porque se você esperar 75 anos de idade para poder the dar uma aposentadoria, para você ganhar salário do Governo aí, está no Rio o cara vai morrer".

A percepção de João não é muito distinta da de Antônio e se centra numa condição de completa despreocupação ou indiferença com o futuro: “(...) vai contribuir, parece que é trinta e cinco anos, não é isso? Aí vai ganhar o mesmo salário. Não é verdade? Eu não tenho condição de pagar para ganhar três, quatro, cinco salários. Para mim, no meu modo de ver, só se eu me aposentar por idade ou por. Vou ter que me aposentar de qualquer jeito direito ou não. Mas eu espero que até lá ainda esteja trabalhando. (...) eu não penso em parar de trabalhar, eu gosto".

\section{CONSIDERAÇÕES FINAIS: AS CONDIÇÕES DE TRABALHO E O CIRCULO DE FERRO DA INFORMALIDADE}

A análise da informalidade sempre se pautou na dualidade com a formalidade, inclusive centrada em melhores ou piores condições de exercício das atividades ou nas condições técnicas médias para desenvolvimento do processo de trabalho. Krein e Proni (2010) fazem a crítica acertada as primeiras categorizações feitas pela OIT que nos primeiros estudos apontava a tese do desaparecimento do setor informal por vias do crescimento econômico. Porém, diante das mudanças ocorridas nas relações de trabalho, emprego e renda, a OIT refez sua definição e mudou o foco, para a promoção do chamado "trabalho decente".

Com a mudança de objetivo da instituição, passou-se a privilegiar as políticas de formalização do trabalho informal, assim como a fiscalização das condições de emprego no SF. Além disso, reconheceu que o trabalho informal é uma realidade que exerce um papel fundamental na geração de ocupações e renda a uma parcela relativamente grande nos países em desenvolvimento (KREIN E PRONI, 2010; OIT, 2002).

A lógica de execução de atividade especializada é rompida na informalidade, assim o conjunto de procedimentos e atuações são vistas a partir da noção de "empreitada", ou seja, a execução de um conjunto de tarefas previamente contratadas: “ (...) eu sei fazer de tudo na área da construção desde a fundação e te 
entrego na chave, eu pinto, faço fundação, faço serragem, faço forma, sou pedreiro, sou carpinteiro, sou terreiro, sou pintor, parte de eletricidade, eu faço só baixa, que eu não me aprofundei para fazer alta né (...)" (Antônio).

A lógica da empreitada permite que o trabalhador informal estabeleça jornadas em conformidade as suas decisões e de estipular a entrega da obra conforme um cronograma acertado entre ele e o contratante, o que se relaciona também aos possíveis compromissos de trabalho que o mesmo pode obter a partir da sua rede de relacionamento e habilidade, assim João nos revela que "(...) devido (...) trabalhar como empreitada" ele estabelece um horário mais flexível de jornada, porém ressalta: “(...) eu não chego nove da manhã e vou embora onze horas, eu não faço isso porque eu tenho [...] responsabilidade [meus] clientes (...) me conhecem, que eu sou uma pessoa muito responsável (...)".

Este ponto de flexibilidade na jornada não se relaciona ao tamanho e intensidade da mesma, o que se molda conforme o tipo de tarefa que o trabalhador executa na empreitada e conforme o tipo de empreitada. Por exemplo, seu Antônio nos relata que "(...) depende, quando eu tenho serviço, no condomínio aqui a gente trabalha às 7 , porque é obrigatório trabalhar as 7 , mas tem obra por aí, onde não é condomínio [onde a jornada é maior] (...) [em locais que não é] condomínio você pode trabalhar à vontade aí eu vou fazer a parte bruta, vou levantar parede, vou levantar e 5 horas da tarde eu falo [para o ajudante] bate um balde de argamassa aí, dois baldes e pode ir embora e eu fico, eu vou aprontar, os banheiros já estão rebocados, mas eu vou fazer outra parte, daí eu velo muro, ligo rádio e escuto alguma coisa e quando eu vou ver já vai dar 21:30, 22 horas, aí eu pego a bicicleta e borá para casa para outro dia também, se for contar na caneta dá [hum..], 14 horas por dia, aqui não, aqui [no condomínio] eu estou descansado, que é só 7 horas porque é obrigatório, tanto que eu falei que não é ruim porque não tem como me cobrar devido horário, aqui horário já mudou, é 8 , meio dia, é duas até cinco, falaram até as 6 [18h], mas não pode é até as 5 [17h] (...)".

A remuneração é muito variável e responde as condições muito especificas e pessoais do trabalhador. Nos três casos analisados temos perfis diferentes, sendo que somente no caso de João observa-se um perfil de "agenciador" de outros trabalhadores, justamente por suas características de qualidade e responsabilidade nas atividades serem mais claramente definidas. Assim, esse ator nos fala que "(...) 
o salário [na empresa em que estava empregado] não dava nem para alimentar os meus filhos direito, não dava para, não dava para nada (...) achei por vontade própria (...) achar uma melhora e a melhora que eu achei foi essa, trabalhar por conta própria". No caso deste perfil de trabalhador informal os rendimentos estariam em torno de dois salários mínimos, os demais se situariam numa faixa menor que está. Segundo João: “(...) se eu trabalhar mais de um mês numa mesma obra, durante o mês dá para tirar uns $R \$ 2.000,00, R \$ 2.500,00$ (...) a gente dá $R \$ 1.400,00$, $\mathrm{R} \$ 1.500,00$ para o ajudante (...)".

A intermediação das "empreitadas" estão relacionadas a rede de contatos do trabalhador informal, o que se relaciona a quatro fatores integrados: i) a habilidade e grau de qualificação do mesmo; ii) a responsabilidade no cumprimento de horários e tempo médio da atividade estabelecida; iii) perfil psicológico do trabalhador; iv) outros fatores que definem relações de rede de contato, especialmente família e religião. Os três entrevistados apresentam perfis referentes aos aspectos acima expostos distintos, não tendo sido tratado nas entrevistas os aspectos de interação em termos de grupo de afinidade religiosa.

As redes de contato muitas vezes não funcionam o que leva o trabalhador a ficar certo período desempregado ou em atividade paralela ao seu ofício principal. $A$ busca pelo emprego constitui um dos pontos importantes, sendo que muitas vezes se estabelece a partir da busca convencional. Antônio, por exemplo, relata que “ (...) [foi] atrás, me apresentei, fui atrás cheguei ai o dono disse, não a gente vai precisar, na fundação, vai começar pedreiro só depois, aí fui no outro dia lá, não, pedreiro ainda não, fui no terceiro dia, um rapaz foi lá como ajudante, de um lugar antigo, mas espancou a mão, trabalhou só até meio dia, almoçou foi embora, no outro dia também, trabalhou até meio dia e não aguentou, aí quando foi em um outro dia, e eu indo todo o dia lá, aí o cara disse cara faz o seguinte, o rapaz veio aqui o não aguentou, vem amanhã para gente fazer um teste, tá bom, daí fiquei lá, espocou a mão, fez calo de sangue, estourou, mas eu fiquei, precisava (...)".

Exemplo de trabalhador que tem uma rede mais ampla de contatos é João, ele nos fala que trabalha para "(...) muito tipo de pessoa (...) para a dona de casa, faço trabalho até, até para doméstica eu faço trabalho. Trabalhos pequenos, claro, não [são] como trabalhar com empresário. Mas eu tenho muitos empresários que eu trabalho também. Obras grandes". Ao ser indagado quanto ao período máximo que 
teria ficado sem trabalhar nos últimos quinze anos ele nos diz que foi no máximo de "três meses".

Com base nas entrevistas foi possível estabelecer alguns parâmetros de análise: i) os entrevistados são unânimes em afirmar que as condições de trabalho nas empresas, ou seja, quando os mesmos estiveram empregados formalmente, são muito precárias e não apresentam "vantagens" ao emprego informal, exceto quanto aos aspectos de intermediação e, em alguns casos, a garantia do pagamento do INSS; ii) não há, pelo menos a partir da história de vida dos entrevistados, barreiras técnicas entre a construção civil formal e informal, o que nos remete a duas ordens de questões: primeiro, a baixa tecnicidade da construção civil brasileira ou pelo menos paraense e; segundo, a formação e qualificação dos trabalhadores se dá em grande medida pelo processo de autoaprendizagem; iii) o grau de intensidade no trabalho constitui o ponto central da diferenciação entre um "regime formal ou quase formal" e o "regime informal de trabalho", porém em ambos os casos as jornadas são superiores as 40 horas semanais tomadas como padrão médio e legal ainda vigente no país.

\section{REFERÊNCIAS BIBLIOGRÁFICAS}

CACCIAMALI, M. C. Globalização e processo de informalidade. Economia e Sociedade, v. 14, 2000.

DIEESE. Nota Técnica no 99 - A Informalidade e o Movimento Sindical: uma agenda para o século XXI. São Paulo, 2011.

KREIN, J. D. \& PRONI, M. W. Economia informal: aspectos conceituais e teóricos. OIT, 2010.

KREIN, J. Dari; PRONI, M. Economia informal: aspectos conceituais e históricos. Brasília: OIT, 2008.

MARQUES, Léa; HENRIQUE, Artur; TEIXEIRA, Daniel; ABÍLIO, Ludmila. Informalidade: realidades e possibilidades para o mercado de trabalho brasileiro. São Paulo: Fundação Perseu Abramo, 2018.

OLIVEIRA, F. Crítica à Razão Dualista. São Paulo: Vozes (1988).

ORGANIZAÇÃO INTERNACIONAL DO TRABALHO. El trabajo decente y la economia informal. OIT, 2002. 
Guidelines concerning a

statistical definition of informal employment, endorsed by the Seventeenth International Conference of Labour Statisticians (November-December 2003) In:

INTERNATIONAL CONFERENCE OF LABOUR STATISTICIANS, 17. Report of the conference. 2003.

SENA, Ana Laura. O Trabalho informal nas ruas e praças de Belém: Estudo sobre o comércio ambulante de produtos alimentícios. Belém: NAEA, 2002.

THEODORO, M. As características do mercado de trabalho e as origens do informal no Brasil. In: SILVA, F. B. da [etal.] [org.]. Questão social e políticas sociais no Brasil contemporâneo. Brasília: Ipea, 2005.

TRINDADE, J. R. B. A metamorfose do trabalho na Amazônia. Belém: Editora da UFPA/NAEA,2001.

VASCONCELOS, E. \& TARGINO, I. A informalidade no mercado de trabalho brasileiro (1993-2013). Revista da ABET, V. 14, N. 1, 2015. 